\title{
DIGITAL RADIOGRAPHIC ASSESSMENT OF KNEE JOINT SPACE WITH ITS CLINICAL SIGNIFICANCES
}

\author{
Mansur $D I^{1^{*}}$, Karki $S^{2}$, Mehta $D K^{3}$, Shrestha $P^{4}$, Maskey $S^{4}$
}

\section{Affiliation}

1. Associate Professor, Department of Anatomy, Kathmandu University School of Medical Sciences, Dhulikhel, Nepal

2. Associate Professor, Department of Radio-diagnosis, Dhulikhel Hospital/Kathmandu University Hospital, Dhulikhel, Nepal

3. Assistant Professor, Department of Anatomy, Kathmandu University School of Medical Sciences, Dhulikhel, Nepal

4. Lecturer, Department of Anatomy, Kathmandu University School of Medical Sciences, Dhulikhel, Nepal

\section{ARTICLE INFO}

Received : 11 March, 2020

Accepted : 17 April, 2020

Published : 30 June, 2020

(c) Authors retain copyright and grant the journal right of first publication with the work simultaneously licensed under Creative Commons Attribution License CC - BY 4.0 that allows others to share the work with an acknowledgment of the work's authorship and initial publication in this journal.

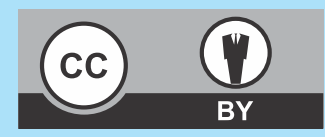

\section{ORA 168}

DOI: https://doi.org/10.3126/bjhs.v5i1.29637

\section{* Corresponding Author}

Dr. Dil Islam Mansur

Associate Professor

Department of Anatomy

Kathmandu University School of Medical Sciences, Dhulikhel, Nepal Email ID: dilislam@kusms.edu.np

ORCID: https://orcid.org/0000-0001-5958-0423

\section{Citation}

Mansur DI, Karki S, Mehta DK, Shrestha P, Maskey S. Digital Radiographic Assessment of Knee Joint Space with its Clinical Significances. BJHS 2020;5(1)11: 976-980.

\section{ABSTRACT}

\section{Introduction}

The knee joint space is seen on anteroposterior radiograph as a radiolucent area between lower end of femur and upper end of tibia which is an indirect way of evaluating the knee cartilage thickness.

\section{Objective}

This study was aimed to determine the knee joint space in the medial and lateral compartments of the knee joint using digital radiograph.

\section{Methodology}

This was cross-sectional study. It consisted of digital radiographs of knee joint of 320 individuals. The medial and lateral joint space width of each knee joint was measured using the scale in the computerized software.

\section{Results}

The mean values for medial and lateral joint space widths were found to be $6.11 \pm 1.57 \mathrm{~mm}$ and $7.92 \pm 1.66 \mathrm{~mm}$ of the right knee joint respectively and $5.99 \pm 1.47 \mathrm{~mm}$ and $8.18 \pm 1.69 \mathrm{~mm}$ of the left knee joint respectively. In males, mean values for joint space widths were $6.37 \pm 1.58 \mathrm{~mm}$ on medial side and $8.21 \pm 1.67 \mathrm{~mm}$ on lateral side of the right knee; and $6.24 \pm 1.56 \mathrm{~mm}$ on medial side and $8.33 \pm 1.64 \mathrm{~mm}$ on lateral side of the left knee. In Females, these values were $5.89 \pm 1.53 \mathrm{~mm}$ on medial side and $7.66 \pm 1.62 \mathrm{~mm}$ on lateral side of the right knee; and $5.79 \pm 1.37 \mathrm{~mm}$ on medial side and $8.06 \pm 1.72 \mathrm{~mm}$ on lateral side of the left knee.

\section{Conclusions}

It was concluded that the lateral joint space was greater than the medial joint space in both knees. The joint space widths were found to be reasonably constant with increasing age among studied population.

\section{KEYWORDS}

Knee, osteoarthritis, radiography 


\section{INTRODUCTION}

The knee is a weight-bearing largest synovial joint in the body. It is compound type of joint as it includes two condylar joints between condyles of femur and tibia; and a saddle joint between patella and the femur. ${ }^{1}$ The distance between the distal end of femur and the proximal end of tibia is known as knee joint space. ${ }^{2}$ It is separated by articular cartilages, menisci and with little contributions from cruciate ligaments. These are collectively seen on anteroposterior radiograph as a radiolucent area between the condyles of femur and tibia. ${ }^{3,4}$

The knee is the most common joint affected by osteoarthritis. It is a major cause of disability in the elderly and approximately $30 \%$ of individuals over the age of 65 are affected worldwide. ${ }^{6}$ It has a higher prevalence and more often generalized in female than male. ${ }^{7}$ It is a slowly progressive degenerative disease characterized by gradual loss of articular cartilage. ${ }^{8}$ As the age grows older, there is gradual increase in the wear and tear of the cartilage and also, a gradual reduction in joint space. ${ }^{9}$ It has been reported to occur at a rate of 0.1 to 0.2 $\mathrm{mm}$ per year in patients with osteoarthritis. ${ }^{10,11}$

The narrowing of the space may be the earliest sign of osteoarthritis. ${ }^{12}$ It is used as a major criterion in the diagnosis of osteoarthritis from radiographs and for monitoring progression of the disease. ${ }^{13}$ It is also of value in the evaluation of disease modifying therapies for osteoarthritis. ${ }^{14}$ The aim of this study was to determine the normal reference values of knee joint space on digital radiographic images of individuals.

\section{METHODOLOGY}

The present study was observational and cross sectional type. It study consisted of digital radiographs of knee joint of 320 (148 males and 172 females) individuals with age group of 20-69 years. It study was conducted in Department of Anatomy and digital radiographs were collected from the Department of Radio-Diagnosis, Dhulikhel Hospital/ Kathmandu University Teaching Hospital, Dhulikhel, Nepal during the period from January to July 2019. The individuals had undergone digital radiographs for the knee complaints that were referred from outpatient department. After making diagnosis of the individuals with normal configuration of articular surfaces of femur and tibia by Radiologist were included for this study. The individuals with any bone or joint pathology such as rheumatoid arthritis or osteoporosis, with history of knee injury or had undergone any knee surgery (arthroscopy or menisectomy etc.) were excluded from the study. Approval from institutional review committee was taken prior to the starting of the study (Ref. no. 158/19).

Sample size was calculated as:

$n=z^{2} \times p(1-p) / e^{2}$

where,

$\mathrm{n}=$ minimum required sample size

$z=1.96$ at $95 \%$ confidence interval

$\mathrm{p}=$ prevalence, $50 \%$

$q=1-p$

$\mathrm{e}=$ margin of error, $6 \%$
Calculated minimum sample size was 266 , however total sample size taken for the study was 320 . The maximum height of the radiolucent area between the radiopaque margins of the articular surfaces of femur and tibia was measured as the maximum joint space width in the midpoint of the medial and lateral compartments of each knee (Figure 1). The measurements were made to the nearest 0.1 $\mathrm{mm}$ using an in-built electronic caliper in millimeter. The obtained data were studied under different age groups. Each ten years grouped as an age group. Hence, the present study consisted of 20-29, 30-39, 40-49, 50-59 and 60-69 years age groups. ${ }^{12}$

The data was analyzed by using Statistical Package for Social Sciences (SPSS) version 23.0 software. The measured data was summarized as mean, standard deviation and range. The correlation between the measured joint space width and sex was determined with analysis of student's t-test and between the measured joint space width and age group was determined by using one way ANOVA.

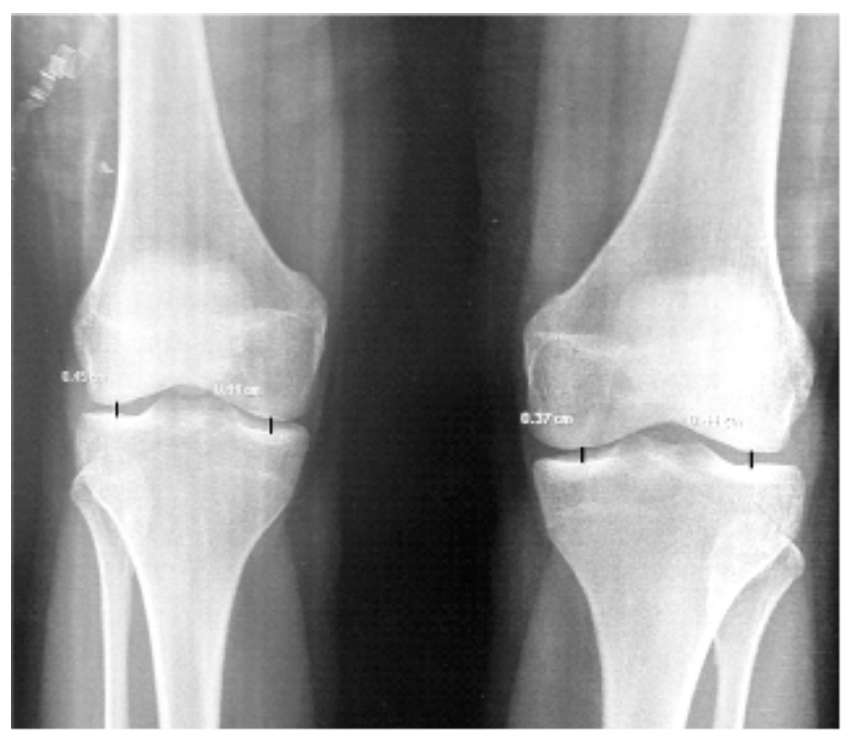

Figure 1: Radiograph of right and left knee joints showing joint space (Black marks).

\section{RESULT}

In the present study, the mean values for medial and lateral joint space width were observed $6.11 \pm 1.57 \mathrm{~mm}$ and $7.92 \pm 1.66 \mathrm{~mm}$ of the right knee joint respectively. The mean values for medial and lateral joint space width were found to be $5.99 \pm 1.47 \mathrm{~mm}$ and $8.18 \pm 1.69 \mathrm{~mm}$ of the left knee joint respectively as shown in table 1 . Hence, it was concluded that the lateral joint space width was greater than the medial joint space width in both knee joints.

Table 1: Descriptive statistics of knee joint space width in millimeter

\begin{tabular}{|l|c|c|c|}
\hline Parameters & Range & Mean \pm SD & p-value \\
\hline rMJS & $2.90-7.10$ & $6.11 \pm 1.57$ & 0.00 \\
\cline { 1 - 3 } rLS & $3.30-8.30$ & $7.92 \pm 1.66$ & \\
\hline IMJS & $2.10-7.60$ & $5.99 \pm 1.47$ & 0.00 \\
\hline ILJS & $4.00-7.50$ & $8.18 \pm 1.69$ & \\
\hline
\end{tabular}


For right knee joint, the mean values of joint space width were $6.37 \pm 1.58 \mathrm{~mm}$ on medial side and $8.21 \pm 1.67 \mathrm{~mm}$ on lateral side among males. Similarly, the mean values for these spaces were found to be $5.89 \pm 1.53 \mathrm{~mm}$ on medial side and $7.66 \pm 1.62 \mathrm{~mm}$ on lateral side among females. It was also observed that the mean values for the medial and lateral joint space widths were found to be higher among males than that of females population. But there were significant gender differences only in medial joint space width as shown in table 2 .

For left knee joint, the mean values of joint space width were $6.24 \pm 1.56 \mathrm{~mm}$ on medial side and $8.33 \pm 1.64 \mathrm{~mm}$ on lateral side among male. Similarly, the mean values for these spaces were found to be $5.79 \pm 1.37 \mathrm{~mm}$ on medial side and $8.06 \pm 1.72 \mathrm{~mm}$ on lateral side among females. It was also concluded that all the mean values for space widths were found to be significantly higher among male than that of female population on medial side of right knee joint as illustrated in table 2.

Table 2: Descriptive statistics of knee joint space width of male and female in millimeter

\begin{tabular}{|c|c|c|c|}
\hline Parameters & Males & Females & p-value \\
\hline rMJS & $6.37 \pm 1.58$ & $5.89 \pm 1.53$ & 0.03 \\
\hline rLJS & $8.21 \pm 1.67$ & $7.66 \pm 1.62$ & 0.19 \\
\hline IMJS & $6.24 \pm 1.56$ & $5.79 \pm 1.37$ & 0.02 \\
\hline ILJS & $8.33 \pm 1.64$ & $8.06 \pm 1.72$ & 0.24 \\
\hline
\end{tabular}

It was observed that all the mean values for joint space widths were statistically insignificant differences between different age groups except right medial joint space where it was found to be significant. Hence, it was found to be reasonably constant with increasing age among studied population as shown in table 3 and figure 2 .

Table 3: Knee joint space widths according to age group in
millimeter
\begin{tabular}{|c|c|c|c|c|c|c|}
\hline $\begin{array}{c}\text { Age } \\
\text { group }\end{array}$ & Total number & rMJS & rLJS & IMJS & ILS \\
\cline { 2 - 7 } & Male & Female & & & & \\
\hline $20-29$ & 46 & 25 & $6.55 \pm 1.58$ & $8.42 \pm 1.79$ & $6.02 \pm 1.34$ & $8.15 \pm 1.65$ \\
\hline $30-39$ & 23 & 24 & $5.76 \pm 1.51$ & $7.66 \pm 1.54$ & $5.70 \pm 1.17$ & $7.61 \pm 1.58$ \\
\hline $40-49$ & 33 & 39 & $6.17 \pm 1.57$ & $8.13 \pm 1.51$ & $6.11 \pm 1.56$ & $8.42 \pm 1.69$ \\
\hline $50-59$ & 14 & 38 & $6.34 \pm 1.69$ & $7.87 \pm 1.74$ & $6.10 \pm 1.35$ & $8.15 \pm 1.64$ \\
\hline $60-69$ & 24 & 29 & $6.02 \pm 1.47$ & $7.79 \pm 1.57$ & $5.87 \pm 1.76$ & $8.17 \pm 1.89$ \\
\hline $70-79$ & 8 & 17 & $5.40 \pm 1.45$ & $7.08 \pm 1.73$ & $5.97 \pm 1.70$ & $8.60 \pm 1.46$ \\
\hline p-value & 148 & 172 & 0.09 & 0.28 & 0.93 & 0.91 \\
\hline
\end{tabular}

Note: $r M J S=$ Right Medial Joint Space, $r$ LJS= Right Lateral Joint Space, IMJS=Left Medial Joint Space, ILJS=Left Lateral Joint Space

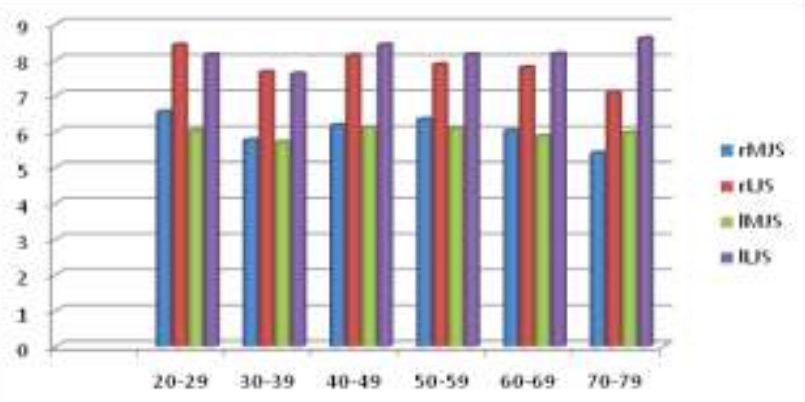

Figure 2: Bar chart showing age group wise knee joint space widths

\section{DISCUSSION}

An osteoarthritis is the more common joint disorder at knee joint which is a leading cause of knee joint space narrowing. ${ }^{15}$ The progression of osteoarthritis is unpredictable in most patients and the progression of joint space narrowing differs greatly between patients. ${ }^{10}$ However, the rapidity of the joint space narrowing eventually has been shown to be associated with increasing of pain and disability. ${ }^{16}$

The evaluation of osteoarthritis is regularly based on examination of pain and functional disability. Neither of these clinical criteria is strongly correlated with the anatomical progression of the disease. However, there is a need of perfect technique for assessing the progression of joint damage in view of the development of disease modifying drugs in osteoarthritis. ${ }^{14}$ The progression of joint space narrowing is considered to be the best available marker of disease progression, provided that an accurate method of evaluation is available. ${ }^{13}$ The measurement of joint space width has become the standard tool for the assessment of knee joint space narrowing. ${ }^{2}$ Conventional X-rays are considered to be sufficient for evaluation of the progression of osteoarthritis. ${ }^{17}$

The present study observed that the mean values for medial joint space was lesser than that of the lateral joint space in both genders. In agreement with the present study, another study also showed the similar findings. ${ }^{18}$ The difference could be explained with the fact that the lateral tibiofemoral cartilage is thicker than that of the medial. ${ }^{3,4}$ It has been reported that the medial compartment is more effective in documenting the progression of osteoarthritis in patients with disease and that the lateral compartment is less sensitive to change. ${ }^{19}$ A study claimed that the lower sensitivity of lateral space narrowing is due to the lower proportion of compressive force supported by lateral part compared to medial part. ${ }^{20}$

The study showed significant difference in medial joint space width among males and females. A study reported that the mean values of medial joint space for males were found to be significantly wider than the mean values for females which is in accordance with the present study. ${ }^{12}$ However another study revealed that the mean values of joint space for males were found to be slightly wider than females, but this difference was not statistically significant which is different from the present study. ${ }^{15}$ Hence, these values would be allowed for local use of the uniform reference values for both genders. This difference could be related to differences in the study design and possible characteristics of study subjects. In the present study, the plain radiographs were taken in erect position while other study used radiographs that were obtained in the supine position for knee joint space width measurements.

In the present study, it was also observed that there was no any increase/decrease in joint space width with increasing age of an individual. A similar study also reported that there was somewhat constant joint space width with increasing age. $^{12}$ Likewise, a study conducted among healthy individuals 
between 40 and 75 years of age reported that the mean values for joint space width were not decreased with increasing decade of life. ${ }^{21}$ However, the knee joint space width was initially increased with advancing age up to 34 years, then there was a progressive decrease with increasing age particularly in the medial compartments. ${ }^{15} \mathrm{~A}$ study also reported decrease in joint space width and cartilage thickness with increasing which is inconsistent with this study. ${ }^{22}$

On the other hand, another cross-sectional study showed no significant reduction in joint space width among healthy individuals with aging. ${ }^{21}$ It provided evidence that osteoarthritis is a specific process and not an inevitable part of aging. In that study, joint space width was measured by metered calipers, a manual method of measurement that may not be sensitive enough to detect changes. In a study, it was observed that the descriptive statistics do not appear to show any differences in mean values for joint space width between decades in either males or females which is in agreement with the present study. ${ }^{12}$ It is well established that age is a strong risk factor for knee osteoarthritis. ${ }^{23}$ Its incidence and prevalence increased 2-10 folds from age 3065 years and increased further thereafter. ${ }^{24}$

Generally, the incidence of osteoarthritis is low below the age of 50 years and high after the age of 50 years. It was also considered that the incidence of osteoarthritis was more prevalent among males before the age of 50 years and among females after the age of 50 years. This may be due to the sex differences in cartilage volumes is a potential explanation for sex variation in incidence. ${ }^{25}$

Although the incidence of osteoarthritis is recorded high with increasing age, the condition is not a normal part of ageing process. With ageing, the articular cartilage shows localized fibrillation and matrix with decreased water content, resulting in loss of cartilage shock absorbing property. Whereas in osteoarthritis the articular cartilage shows fibrillation, fragmentation and loss of cartilage thickness such as osteophytes subchondral sclerosis, subchondral cysts and formation of fibro-cartilagenous tissue repair. ${ }^{7}$ Moreover, a study claimed that osteoarthritic changes are not directly linked with advanced aging. But these changes

\section{REFERENCES}

1. Standring S. Gray's Anatomy, 40th edition. Elsevier Limited: Churchill Livingstone; 2008:1393-1410.

2. Peterfy CG. Imaging of the disease process. Curr Opin Rheumatol. 2002;14(5):590-6. DOI: 10.1097/00002281-200209000-00020

3. Ryan S, Nicholas MM, Eustace S. The knee joint. In: Anatomy for diagnostic imaging. London: Elsevier Limited 2004:286-89.

4. Butler P, Mitchell PWM, Ellis H. The knee Joint. In: Applied radiological anatomy. Cambridge: Cambridge University Press. 1999:363-6.

5. Jordan KM, Arden NK, Doherty M, Bannwarth B, Bijlsma JW, Dieppe $P$, et al. EULAR Recommendations 2003: An evidence based approach to the management of knee osteoarthritis: Report of a Task Force of the Standing Committee for International Clinical Studies Including Therapeutic Trials (ESCISIT). Ann Rheum Dis. 2003;62(12):1145-55. DOI: 10.1136/ard.2003.011742 may be occurred when associated with certain precipitating factors such as abnormal stresses, abnormal shape of the bones of the joint, muscle weakness or neurological deficit or dysfunction. $^{26}$

\section{CONCLUSION}

The present study showed that all the individuals have larger lateral knee joint spaces than medial knee joint spaces. Male had slightly larger knee joint spaces than female. There was no reduction in the knee joint space with increasing age. The accurate knowledge of knee joint space may be used in diagnosis and treatment of knee cartilage diseases. It could also establish normal reference values of knee joint space width which may help in further research activities.

\section{RECOMMENDATIONS}

This study recommends an increase in sample size and conduct in other parts of country to generalize the results for Nepalese population.

\section{LIMITATIONS OF THE STUDY}

It was conducted only in individuals with normal knee joint configuration with an age group of 20-69 yrs. There is a need for evaluation of knee joint space width in children and knee cartilage diseases.

\section{ACKNOWLEDGEMENT}

The authors would like to acknowledge the faculties and staffs of Department of Radio-diagnosis, Dhulikhel hospital/Kathmandu University Hospital for diagnosis and providing normal radiographic images of knee joint to conduct this study. The authors would also like to thank Dr. Bishal Sah, Resident in Department of Anatomy, for helping in data collection and preparing the manuscript.

\section{CONFLICT OFINTEREST}

There are no conflicts associated with this study.

\section{FINANCIAL DISCLOSURE}

This is a self funded study

6. Lawrence RC, Hochberg MC, Kelsey JL, McDuffie FC, Medsger TA, Felts WR, et al. Estimates of the prevalence of selected arthritis and musculoskeletal diseases in the United States. J Rheumatol. 1989;16 (4):427-41. DOI: 10.1002/1529-0131(199805)41:5<778:: AIDART4>3.0.CO;2-V

7. Pulivarthi H, Maddikunta V, Koteswara Rao P. Variations in radiographic appearance of articular cartilage of knee joints in persons of 35 to 65 years of age. Int J Res Med Sci. 2015;3(1):22-6. DOI: 10.5455/2320-6012.ijrms20150104

8. Hunter DJ, Zhang YQ, Niu JB, Tu X, Amin S, Clancy M, et al. The association of meniscal pathologic changes with cartilage loss in symptomatic knee osteoarthritis. Arthritis Rheum. 2006;54(3):795801. DOI: 10.1002 /art.21724 
9. Sargon MF, Taner D, Altinta K. Examination of joint space by magnetic resonance imaging in anatomically normal knees. Clin Anat. 1998;9(6):386-90. DOI: 10.1002/(SICI)1098-2353(1996)9:6 <386: AID-CA5 >3.0.CO;2-9

10. Lequesne M. Osteoarthritic disorders. 1st ed. American Academy of Orthopaedic Surgeons; Illinois. Quantitative measurements of joint space during progression of osteoarthritis: "Chondrometry"; 1995: 427.

11. Sharma L, Song J, Felson DT, Cahue S, Shamiyeh MS, Dunlop DD. The role of knee alignment in disease progression and functional decline in knee osteoarthritis. Journal of the American Medical Association. 2001;286:188-95. DOI: 10.1001/jama.286.2.188

12. Beattie KA, Duryea J, Pui M, O'Neill J, Boulos P, Webber CE, et al. Minimum joint space width and tibial cartilage morphology in the knees of healthy individuals: a cross-sectional study. BMC Musculoskelet Disord. 2008;9:119-26. DOI: 10.1186/1471-2474-9-119

13. Altman RD, Fries JF, Bloch DA, Carstens J, Cooke TD, Genant H, et al. Radiographic assessment of progression in osteoarthritis. Arthritis Rheum. 1987;30(11):1214-25. DOI: 10.1002/art.1780301103

14. Hilliquinb P, Pessisc E, Costed J, Maugetc D, Azriab A, Chevrotc A, et al. Quantitative assessment of joint space width with an electronic caliper. Osteoarthritis and Cartilage. 2002; 10: 542-46. doi:10.1053/ joca.2002.0809

15. Anas I, Musa TA, Kabiru I, Yisau AA, Kazaure IS, Abbaa SM, et al. Digital radiographic measurement of normal knee joint space in adults at Kano, Nigeria. The Egyptian J Radiol Nuclear Med. 2013;44:253-8. https://doi.org/10.1016/j.ejrnm.2013.03.005

16. Dougados M, Gueguen A, Nguyen M, Thiesce A, Listrat V, Jacob L, et al. Longitudinal radiologic evaluation of osteoarthritis of the knee. J Rheumatol. 1992;19(3):378-84. PMID: 1578451

17. Martel W, Adler RS, Chan K, Niklason L, Helvie MA, Jonsson K. Overview: New methods in imaging osteoarthritis. J Rheumatol. 1991;18(suppl.): 32-7. PMID: 2027123

18. Koo S, Gold GE, Andriacchi TP. Considerations in measuring cartilage thickness using MRI: factors influencing reproducibility and accuracy. Osteoarthr Cartilage. 2005;13:782-9. DOI: 10.1016/j.joca.2005.04.013
19. Ravaud P, Chastang C, Auleley GR, Giraudeau B, Royant V, Amor B, et al. Knee joint space width measurement: An experimental study of the influence of radiographic procedure and joint positioning. $\mathrm{Br} J$ Rheumatol. 1996;35(8):761-6. PMID: 8761189

20. Oksendahl HL, Gomez N, Thomas CS, Badger GD, Hulstyn MJ, Fadale $\mathrm{PD}$, et al. Digital radiographic assessment of tibiofemoral joint space width: A variance component analysis. J Knee Surg. 2009;22(3):20512. PMID: 19634723

21. Lanyon P, O'Reilly S, Jones A, Doherty M. Radiographic assessment of symptomatic knee osteoarthritis in the community: definitions and normal joint space. Ann Rheum Dis. 1998;57(10):595-601. DOI: 10.1136/ard.57.10.595

22. Gensburger D, Arlot M, Sornay-Rendu E, Roux J, Delmas P. Radiologic assessment of age-related knee joint space changes in women: a 4year longitudinal study. Arthritis Rheum. 2009;61(3):336-43. https:// doi.org/10.1002/art.24342

23. Felson DT, Lawrence RC, Dieppe PA, Hirsch R, Helmick CG, Jordan JM, et al. Osteoarthritis: new insights. Part 1: the disease and its risk factors. Ann Intern Med. 2000;133:635-46. DOI: 10.7326/00034819-133-8-200010170-00016

24. Oliveria SA, Felson DT, Reed JI, Cirillo PA, Walker AM. Incidence of symptomatic hand, hip, and knee osteoarthritis among patients in a health maintenance organization. Arthritis Rheum. 1995;38:113441. DOI: $10.1002 /$ art.1780380817

25. Ding C, Cicuttini F, Scott F, Mike G, Jones G. Sex differences in knee cartilage volume in adults: role of body and bone size, age and physical activity. Rheumatology. 2003;42(11):1317-23. https:// doi.org/10.1093/rheumatology/keg374

26. Koster IM, Oei EHG, Hensen JHJ, Boks SS, Koes BW, Vroegindeweij D, et al. Predictive factors for new onset or progression of knee osteoarthritis one year after trauma: MRI follow-up in general practice. Eur Radiol. 2011;21(7):1509-16. doi: 10.1007/s00330-0112089-3. 